Original article

\title{
Circadian melatonin secretion in obese adolescents with or without obstructive sleep apnea
}

\author{
Olga N. Berdina, Irina M. Madaeva, Svetlana E. Bolshakova, Maria V. Tsykunova, Leonid F. Sholokhov, Maria A. \\ Rashidova, Olga V. Bugun, Lyubov V. Rychkova
}

Scientific Centre for Family Health and Human Reproduction Problems, Irkutsk, Russia

Received 26 May 2020, Revised 21 September 2020, Accepted 5 November 2020

(c) 2020, Berdina O.N., Madaeva I.M., Bolshakova S.E., Tsykunova M.V., Sholokhov L.F., Rashidova M.A., Bugun O.V., Rychkova L.V.
(C) 2020, Russian Open Medical Journal

Abstract: Objective - To compare melatonin levels in saliva during a 24-hr day in order to identify the specificities of circadian melatonin secretion in obese adolescents with or without obstructive sleep apnea (OSA).

Material and Methods - We examined 18 obese adolescents with OSA, 12 obese adolescents without OSA, and 15 healthy adolescents with a normal body weight, from whom saliva was sampled four time during the 24-hr day. Polysomnography was used to diagnose OSA. Saliva samples $(n=180)$ were subjected to enzyme-linked immunosorbent assay.

Results - Obese adolescents with OSA had higher evening melatonin levels than obese adolescents without OSA. For example, this indicator in OSA patients was 5.3 times higher than in participants without OSA, who had the lowest evening melatonin level among all groups. In both obese groups, nighttime melatonin levels were significantly lower than in the control group. A positive correlation was detected between the levels of morning and afternoon melatonin and body mass index only in obese adolescents without OSA ( $r=0.58$; $p=0.03$ and $r=0.68 ; p=0.01$, respectively). It was found that evening melatonin correlated with minimum blood oxygen saturation $\left(\mathrm{SaO}_{2}\right)$ in the entire sample of adolescents with OSA ( $r=-0.69 ; p=0.008)$, and it also correlated with time with $\mathrm{SaO}_{2}<90 \%$ in the group with clinical manifestations of OSA ( $r=0.76 ; p=0.003)$. Nighttime melatonin levels negatively correlated with the minimum $\mathrm{SaO}_{2}$ value solely in the group with clinical manifestations of OSA ( $r=-0.58 ; p=0.035)$.

Conclusion - The circadian melatonin secretion in obese adolescents differed, depending on the presence or absence of OSA, and correlated with the level of oxygen desaturation in OSA patients, to a greater extent - in the presence of clinical manifestations.

Keywords: obstructive sleep apnea, obesity, melatonin, adolescents.

Cite as Berdina ON, Madaeva IM, Bolshakova SE, Tsykunova MV, Sholokhov LF, Rashidova MA, Bugun OV, Rychkova LV. Circadian melatonin secretion in obese adolescents with or without obstructive sleep apnea. Russian Open Medical Journal 2020; 9: e0402.

Correspondence to Olga N. Berdina. Address: Scientific Centre for Family Health and Human Reproduction Problems, 16 Timiryazeva St., Irkutsk 664003 , Russian Federation. Phone: +7 (3952) 207636. E-mail: goodnight 84@mail.ru.

\section{Introduction}

Obstructive sleep apnea (OSA) is a condition, characterized by recurrent episodes of upper airway obstruction and arousals, as well as by decreased oxygen saturation during sleep [1]. Repeated bouts of apnea/hypopnea, combined with awakening, result in sleep fragmentation and reduced sleep duration and quality. Some studies have shown a significant relationship between OSA and obesity [2-4]. These ailments lead to disruption of circadian rhythms and, as a consequence, to changes in the melatonin production during the 24-hr day, a decrease in the quality of life, etc. [5-9].

It is known that a large amount of melatonin is secreted by the pineal gland at night. Melatonin regulates a number of important central and peripheral processes associated with cyclic secretion. In addition, it can be important for slowing down the aging process, acting as an antioxidant, and can affect the regulation of the endocrine, reproductive, cardiovascular and immune systems, which could change in some pathological conditions [10, 11]. Exposure to artificial light source dramatically suppresses the release of melatonin at night. Studies on model animals and on humans have shown that melatonin secretion is closely related to sleep quality $[12,13]$. Since OSA is known to alter the endogenous biological clock, and obesity may result from disorder of circadian rhythms, changes in melatonin secretion, simultaneously associated with OSA and obesity, are a very relevant topic for a study. However, there were no studies of circadian melatonin secretion in obese adolescents with OSA. Hence, the objective of our study was to reveal melatonin level dynamics in saliva over the 24-yr day in adolescents with or without OSA, in order to identify the specificities of circadian secretion of this hormone in obese subjects with or without OSA. We hypothesized that circadian melatonin secretion in obese patients would differ, depending on the presence or absence of OSA, and would correlate with some 
polysomnographic parameters, associated with OSA, in patients with simultaneous obesity and OSA.

\section{Material and Methods}

\section{Study participants}

The cross-sectional study design was applied to a survey of adolescents admitted to the Clinic at Scientific Centre for Family Health and Human Reproduction Problems (SC FHHRP) over the period from November 2017 through April 2018 due to obesity and other health conditions, a total of 45 male adolescents 15-17 years old. Participants with OAS $(n=18)$ were recruited from the Somnology Center of SC FHHRP. The control groups with obesity $(n=12)$ and normal body mass - NBM $(n=15)$ included adolescents without episodes of snoring, OSA and with normal results of polysomnography (PSG) screening. It should be noted that OSA has sexual dimorphism [14], and men are especially vulnerable to OSA, so we included just boys in our study. All subjects underwent anthropometric measurements, questionnaires, PSG screening, and serial saliva sampling. The study was carried out over a single 24-hr day.

Inclusion criteria for the study were: a) boys $15-17$ years old; $b$ ) body mass index (BMI) $z$-score $>2$ for corresponding age and gender for both obesity groups, or BMI z-score from -2 to +1 for the corresponding age and gender for the control group with NBM [15]; c) apnea/hypopnea index $\geq 2$ for OSA [16]; d) signed voluntary informed consent. Exclusion criteria for study included the following: a) presence of sleep disorders other than OSA; b) taking exogenous melatonin, L-tryptophan, or sleeping draughts in two weeks preceding the study.

\section{Measurements and procedures}

We conducted questionnaires, anthropometric measurements, PSG, serial saliva sampling, melatonin level measurement, and statistical data processing.

\section{Survey}

The Adolescent Sleep Habits Survey (ASHS) was used to qualitatively assess habitual sleep and wakefulness, as well as its disturbances.

\section{Anthropometric measurements}

The anthropometric parameters (body mass and linear height) of youths were assessed, and BMI $\left(\mathrm{kg} / \mathrm{m}^{2}\right)$ was computed. Assessment of height and weight was carried out using weight-forage reference curves sensu World Health Organization (WHO 2007) and the WHO AnthroPlus calculator. Weight status was determined by the value of the z-score [15].

\section{Polysomnography}

PSG screening was performed at the Somnology Center overnight using a stationary Grass-Telefactor TWin ${ }^{\circledR}$ PSG system (Comet) with an AS40 amplifier with a built-in SPM-1 sleep module (USA). PSG included recordings of: a) six leads of an electroencephalogram (EEG) ( $\mathrm{Fp3} / \mathrm{Fp} 4, \mathrm{C} 3 / \mathrm{C} 4$, referring to $\mathrm{O} 2 / \mathrm{O} 1$, respectively), b) electrooculogram (EOG), c) electromyogram (EMG) of submental muscles and tibialis anterior muscle, d) oronasal airflow pressure, e) snoring, f) thoracoabdominal breathing and g) blood oxygenation (saturation). The study was conducted in accordance with the recommendations of the American Academy of Sleep Medicine (AASM) [17]. Obstructive apnea was defined as a decrease in airflow of at least $90 \%$ for more than 10 seconds, and hypopnea was defined as a reduction in airflow of at least 30\%, accompanied by a decline in oxygen saturation by $3 \%$. The total number of apnea and hypopnea divided by the number of sleep hours was defined as the apnea and hypopnea index (AHI), the total number of EEG activations (arousals) per sleep hour was defined as the total activation index (Al).

\section{Biomaterial sampling}

Saliva samples for measuring melatonin levels were collected from each subject four times over 24-hr period: at 6-7 a.m., 12 noon-1 p.m., 6-7 p.m. and 11 p.m.-12 midnight [18]. To collect samples of biomaterial, special test tubes (SaliCaps, IBL International $\mathrm{GmbH}$, Hamburg, Germany) were used, on which the subject's code and time of collection were indicated beforehand. Study participants were instructed on how to collect and store samples prior to delivery to the research center.

\section{Measuring melatonin level in salivo}

The biomaterial was stored at $-40^{\circ} \mathrm{C}$ until the analysis conducted at the laboratory. Melatonin levels $(\mathrm{pg} / \mathrm{mL})$ in saliva samples were measured by enzyme-linked immunosorbent assay (ELISA), using a commercial BÜHLMANN kit (BÜHLMANN Laboratories AG, Schönenbuch, Switzerland) on ELX808 ${ }^{\mathrm{TM}}$ Absorbance Microplate Reader (BioTek Instruments, Inc., VT, USA).

\section{Statistical analysis}

For statistical data processing, we used Statistica 10.0 software (StatSoft, Inc., USA).

The Kolmogorov-Smirnov test was employed to test the distribution (normal or abnormal) of the variables, and parametric or nonparametric methods were used, as needed. Data were expressed as frequencies or percentages, mean with standard deviation ( $M \pm S D$ ), median (Me), lower quartile (LQ), upper quartile (UQ), minimum (Min), and maximum (Max). Comparisons of continuous variables among three groups (OSA group, obesity control group, NBM control group) were performed using one-way analysis of variance (ANOVA) or nonparametric Kruskal-Wallis $H$ test $(\mathrm{KW}-\mathrm{H})$. The Pearson's $\chi^{2}$ test was used to compare participants for presence of 'sleep problems' versus 'daytime problems' (yes/no). The Spearman's rank-order correlation method was used to analyze the relationship between melatonin levels at four time points vs. BMI depending on the presence or absence of OSA, as well as among melatonin content and PSG indicators, associated with OSA (AHI, minimum $\mathrm{SaO}_{2}$, time with $\mathrm{SaO}_{2}<90 \%$ and total $\mathrm{Al}$ ), in all adolescents with obesity and OSA; and also among the levels of melatonin and aforementioned PSG indicators in groups with and without clinical manifestations of OSA. 

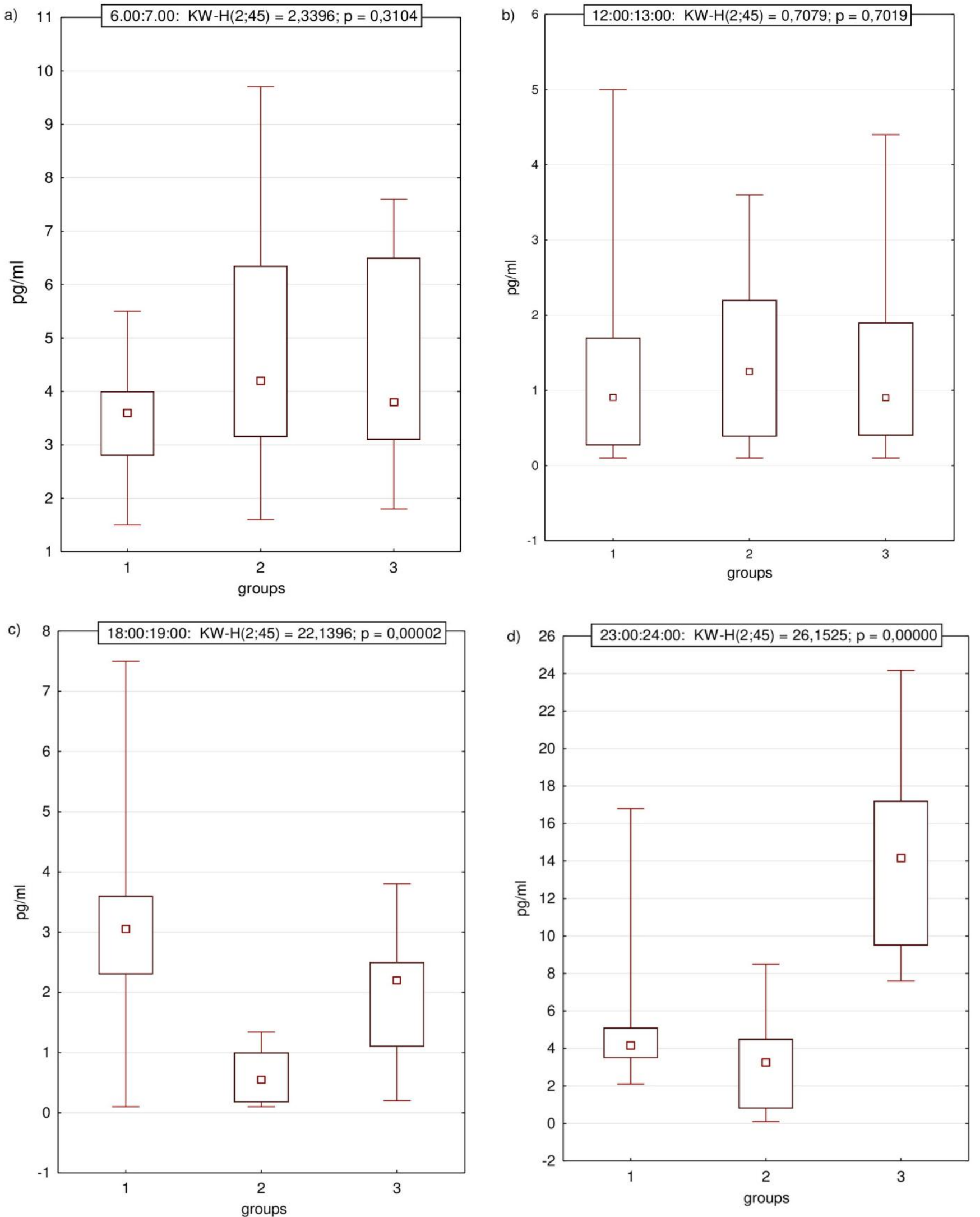

Figure 1. Boxplot diagrams showing median, upper and lower quartiles, minimum and maximum salivary melatonin levels.

a) morning; b) noon; c) evening; d) night for each group of participants (1 - obese group with OSA; 2 - obese control group without OSA; 3 - control group with NBM). OSA, obstructive sleep apnea; NBM, normal body mass. 
Table 1. Comparison of study groups by gender, age, BMI, ASHS scores and main PSG indicators

\begin{tabular}{|c|c|c|c|c|c|c|}
\hline Indicators & $\begin{array}{c}\text { Group with OSA }(n=18) \\
\text { (1) }\end{array}$ & $\begin{array}{l}\text { Obese control group }(n=12) \\
\text { (2) }\end{array}$ & $\begin{array}{c}\text { Control group with NBM }(n=15) \\
\text { (3) }\end{array}$ & $\begin{array}{r}p \text {-value } \\
1 \text { vs. } 2\end{array}$ & $\begin{array}{r}p \text {-value } \\
1 \text { vs. } 3\end{array}$ & $\begin{array}{r}p \text {-value } \\
2 \text { vs. } 3\end{array}$ \\
\hline Age, yr & $16.2 \pm 0.3$ & $16.1 \pm 0.2$ & $16.0 \pm 0.7$ & 0.819 & 0.542 & 0.726 \\
\hline BMI z-score & $2.5 \pm 0.2$ & $2.4 \pm 0.1$ & $-0.09 \pm 0.3$ & 0.778 & $<0.001$ & $<0.001$ \\
\hline \multicolumn{7}{|l|}{ ASHS, $\mathrm{n} / \%$} \\
\hline Nonclinical & $10 / 55.5$ & $10 / 83.4$ & 14/93.3 & 0.114 & 0.016 & 0.412 \\
\hline Clinical & $8 / 44.5$ & 2/16.6 & $1 / 6.7$ & & & \\
\hline \multicolumn{7}{|l|}{ eep indicators } \\
\hline Minimum $\mathrm{SaO}_{2}, \%$ & $84.2 \pm 1.2$ & $95.3 \pm 0.3$ & $96.0 \pm 0.7$ & $<0.001$ & $<0.001$ & 0.389 \\
\hline Time with $\mathrm{SaO}_{2}<90 \%$, \% TST & $3.4(1.6,4.4)$ & $0.0(0.0,0.0)$ & $0.0(0.0,0.0)$ & $<0.001$ & $<0.001$ & - \\
\hline Al, episodes per hr & $28.8 \pm 2.7$ & $16.5 \pm 1.2$ & $14.1 \pm 1.5$ & $<0.001$ & $<0.001$ & 0.623 \\
\hline $\mathrm{TST}, \min$ & $428.2 \pm 35.8$ & $421.1 \pm 37.9$ & $423 \pm 41.1$ & 0.146 & 0.278 & 0.833 \\
\hline $\mathrm{SE}, \%$ & $87.3(81.2,89.5)$ & $92.9(88.4,94.6)$ & $94.0(90.7,96.3)$ & 0.171 & 0.097 & 0.789 \\
\hline $\mathrm{C} 1-\mathrm{C} 2, \% \mathrm{TST}$ & $74.0 \pm 9.3$ & $55.6 \pm 7.2$ & $54.1 \pm 3.8$ & $<0.001$ & $<0.001$ & 0.705 \\
\hline Delta sleep, \% TST & $12.2 \pm 2.3$ & $21.8 \pm 1.2$ & $23.2 \pm 2.0$ & $<0.001$ & $<0.001$ & 0.873 \\
\hline REMS, \% TST & $12.9 \pm 2.7$ & $21.7 \pm 3.5$ & $21.3 \pm 2.8$ & $<0.001$ & $<0.001$ & 0.967 \\
\hline
\end{tabular}

Data are presented as mean value with standard deviation ( $\mathrm{M} \pm \mathrm{SD}$ ), numbers / \%, or medians with lower and upper quartiles (Me (LQ, UQ)).

OSA,obstructive sleep apnea; NBM, normal body mass; ASHS, Adolescent Sleep Habits Survey; BMI, body mass index; AHI, apnea and hypopnea index; min $\mathrm{SaO} 2$, minimum oxygen saturation measured by pulse oximetry; Al, total EEG activation index (total sleep + REM sleep); TST, total sleep time; SE, sleep efficiency; C1 and C2, first and second sleep stages; REMS, Rapid eye movement sleep; Nonclinical, "sleep problems" and "daytime problems" were absent in self-evaluation; Clinical, "sleep problems" and "daytime problems" were reported by the subjects.

Table 2. Correlations between melatonin levels at four time points and OSA-associated PSG indicators in the general group of adolescents with OSA

\begin{tabular}{|c|c|c|c|c|}
\hline Indicators & $\mathrm{AHI}$ & Minimum $\mathrm{SaO}_{2}$ & Time with $\mathrm{SaO}_{2}<90 \%$ & Total Al \\
\hline Morning melatonin level, $\mathrm{pg} / \mathrm{mL}$ & $-0.174(p=0.489)$ & $-0.211(p=0.401)$ & $0.377(p=0.262)$ & $-0.341(p=0.206)$ \\
\hline Daytime melatonin level, $\mathrm{pg} / \mathrm{mL}$ & $0.179(p=0.477)$ & $-0.089(p=0.724)$ & $0.147(p=0.561)$ & $0.056(p=0.825)$ \\
\hline Evening melatonin level, pg/mL & $0.146(p=0.562)$ & $-0.541(p=0.021)$ & $0.192(p=0.446)$ & $-0.156(p=0.536)$ \\
\hline Nighttime melatonin level, $\mathrm{pg} / \mathrm{mL}$ & $-0.071(p=0.779)$ & $0.247(p=0.323)$ & $-0.036(p=0.886)$ & $-0.151(p=0.548)$ \\
\hline
\end{tabular}

Data are presented as Spearman's rank-order correlation coefficients with p-values.

OSA, obstructive sleep apnea; PSG, polysomnography; $\mathrm{AHI}$, apnea and hypopnea index; minimum SaO2, minimum blood oxygen saturation according to pulse oximetry data; total Al, total index of EEG activations.

Table 3. Correlations between melatonin levels at four time points and OSA-associated PSG indicators in groups of adolescents with or without clinical manifestations of OSA

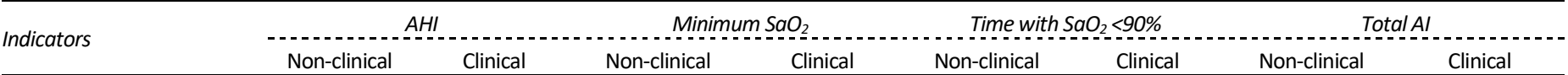

Morning melatonin, $p g / m L \quad 0.211(p=0.558)-0.063(p=0.883) \quad-0.073(p=0.841) \quad-0.285(p=0.494) \quad-0.339(p=0.338) \quad 0.155(p=0.713) \quad 0.112(p=0.758) \quad-0.618(p=0.103)$ Daytime melatonin, $p g / m L \quad 0.017(p=0.977) \quad 0.192(p=0.649) \quad-0.149(p=0.681) \quad 0.384(p=0.347) \quad-0.123(p=0.735) \quad 0.187(p=0.657) \quad-0.019(p=0.958) \quad-0.041(p=0.924)$ Evening melatonin, $p g / m L \quad 0.394(p=0.261) \quad 0.026(p=0.952) \quad-0.584(p=0.037) \quad-0.608(p=0.027) \quad-0.051(p=0.906) \quad 0.766(p=0.009) \quad 0.441(p=0.203) \quad-0.351(p=0.395)$ Nighttime melatonin, $p g / m L \quad 0.089(p=0.808)-0.304(p=0.464) \quad 0.081(p=0.824) \quad-0.505(p=0.042) \quad 0.132(p=0.716) \quad-0.173(p=0.681) \quad 0.031(p=0.932) \quad-0.303(p=0.465)$

Data are presented as Spearman's rank-order correlation coefficients with $p$-values.

OSA, obstructive sleep apnea; PSG, polysomnography; AHI, apnea and hypopnea index; minimum SaO2, minimum blood oxygen saturation according to pulse oximetry data; total $\mathrm{Al}$, total index of EEG activations.

\section{Results}

\section{Patient characteristics}

Baseline characteristics, and ASHS and PSG data for the groups are presented in Table 1. Comparative analysis of the main characteristics showed that patients with obesity and OSA did not significantly differ in age from participants without OSA and from the control group with NBM. As expected, the BMI z-score was significantly different in non-obese adolescents compared with both obese groups $(p<0.0001)$, but did not differ between patients with and without OSA. According to sleep self-evaluation, 'sleep problems' were noted by a much greater proportion of adolescents with OSA than in the control group with NBM, but not in the control group with obese subjects $(p=0.016$ and $p=0.114$, respectively). However, when comparing PSG indicators in the groups, statistically significant differences were revealed in superficial and deep sleep, sleep with rapid eye movements, sleep efficiency, $\mathrm{AHI}$, time with $\mathrm{SaO}_{2}<90 \%$, minimum $\mathrm{SaO}_{2}$ and $\mathrm{Al}$ in patients with OSA, relative to both control groups without OSA.

\section{Salivary melatonin levels}

A comparison of salivary melatonin levels during the 24-hr day between obese adolescents with OSA (1), obese subjects without OSA (2) and the control group with NBM (3) is shown in the Figure 1.

Obese patients with OSA had significantly higher evening melatonin levels $(\mathrm{KW}-\mathrm{H}(2.45)=22.139, \mathrm{p}<0.001)$ and a tendency towards higher night melatonin levels, compared with the obese control group. Obese patients without OSA had the lowest evening melatonin content among all groups of examined youths, which was statistically significantly lower than in the group with OSA, but 
did not statistically differ from the values of the control group with NBM. Also, such patients tended to have higher morning melatonin levels $(\mathrm{KW}-\mathrm{H}(2.45)=2.339, \mathrm{p}=0.310)$ than their obese peers with OSA. Meanwhile, in both obese groups, nighttime melatonin levels were significantly lower than in the NBM control group $(\mathrm{KW}-\mathrm{H}(2.45)=26.152, \mathrm{p}<0.001)$.

Spearman's rank-order correlation coefficient was calculated to assess the relationships between circadian melatonin secretion and $\mathrm{BMI}$ (depending on the presence or absence of OSA), as well as OSAassociated PSG indicators (AHI, minimum $\mathrm{SaO}_{2}$, time with $\mathrm{SaO}_{2}<90 \%$ and total Al) - only in adolescents with obesity and OSA (Table 2).

Statistically significant positive correlations were found between BMI and melatonin levels in the morning and at noon only in obese adolescents without OSA ( $r=0.583, p=0.036$; and $r=0.682, p=0.012$, respectively). The analysis of the relationships between melatonin secretion and OSA-associated PSG parameters showed that evening melatonin levels were significantly correlated with the minimum $\mathrm{SaO}_{2} \quad(\mathrm{r}=-0.541 ; \mathrm{p}=0.021)$. Other PSG parameters, associated with OSA, such as $\mathrm{AHI}$, time with $\mathrm{SaO}_{2}$ $<90 \%$, and total $\mathrm{Al}$, did not correlate with daily dynamics of melatonin levels. Nighttime melatonin levels did not correlate with $\mathrm{BMI}$ or parameters, associated with OSA.

When we compared correlation strength values between circadian melatonin secretion and OSA-related PSG indicators in adolescents with and without clinical manifestations of OSA, no significant differences were found (Table 3), although evening melatonin levels negatively correlated with the minimum $\mathrm{SaO}_{2}$ value, in adolescents with and without clinical manifestations of OSA ( $r=-0.608, p=0.027 ; r=-0.584, p=0.037$, correspondingly). Moreover, the correlation analysis in the OSA group demonstrated a significant relationship between the concentration of nighttime melatonin content and minimum $\mathrm{SaO}_{2}(r=-0.505 ; p=0.042)$, as well as between the evening melatonin levels and time with $\mathrm{SaO}_{2}<90 \%$ $(r=0.766 ; p=0.009)$, compared with non-OSA subjects.

\section{Discussion}

Our focus in this study was to examine the effect of OSA and/or obesity on circadian melatonin secretion in adolescents. We hypothesized that salivary melatonin levels over the 24-yr day in obese patients would differ, depending on the presence or absence of OSA, and would correlate with some OSA-associated PSG parameters.

It should be noted that significant differences in melatonin production over the 24-hr cycle could be the result of various ailments. In our study, we found that both obesity and OSA affect circadian melatonin secretion, which showed a trend towards higher evening melatonin levels in patients with OSA, as well as a tendency towards higher morning melatonin concentration in obese youths without OSA. However, unlike the control group of adolescents with NBM, the presence of a peak in nighttime melatonin secretion was not found in both obese groups. These results are similar to those in the study by Barnaś et al. [19], conducted on middle-aged obese patients with OSA, which have found higher melatonin content during the day and lower melatonin concentration at night in these subjects than in the control group.

Meanwhile, Wikner et al. [20] showed that, in patients with OSA, neither the circadian rhythm of melatonin, nor the nocturnal melatonin concentration in blood serum, differ significantly from those in healthy people. After examining more recent publications on circadian rhythm of melatonin secretion in patients with OSA, we found that our results were at odds with the data of Wikner et al., as well as Brzecka et al. for adult patients with OSA. The authors found a tendency for an increase in melatonin concentration in the morning in $27 \%$ of patients with OSA, while only in $6 \%$ of the study subjects in the evening.

Hernandez et al. [7] and Zirlik et al. [21] described a morning serum melatonin peak at 6 a.m. in OSA patients. However, in individuals with nocturnal peak serum melatonin concentration, AHI was higher [5]. In contrast, we discovered that salivary melatonin level at night (11 p.m. to midnight) was significantly lower in obese patients (both OSA group and non-OSA groups) than in the NBM control group, and found a correlation between evening (6-7 p.m.) level of melatonin in saliva and the severity of desaturation in patients with OSA. The latter in our study did not correlated with the nighttime melatonin secretion.

It is known that the maximum melatonin production occurs in the dark. This hormone is central to chronobiology, being the main regulator of circadian rhythms. Impaired melatonin secretion may lead to disruption of the sleep-wake cycle $[22,23]$. A deficiency in nighttime melatonin production in OSA patients, as well as increased evening melatonin levels, may explain daytime sleepiness and very rapid falling asleep (usually less than five minutes) in obese adolescents with clinical manifestations of OSA. However, nocturnal hypoxemia and repetitive arousal reactions are also major contributors to these changes. It is worth mentioning that the disrupted sleep-wake cycle is a key pattern in both obese patients with OSA and obese patients without it.

The change in the circadian melatonin production, found in obese adolescents in our study, is likely associated with causes other than OSA. This is not directly related to sleep because, unlike some studies $[4,24]$, we did not find any sleep problems in nonOSA obese adolescents. Melatonin provides regulation and synchronization of metabolic processes, has antioxidant and antiinflammatory effects. A quantitative decrease in its level and/or a change in its secretion rhythm can lead to the development of various metabolic disorders, including obesity [25]. It is known that introduction of melatonin is the main element of therapy for both metabolic syndrome and obesity [26-28]. The Corbalán-Tutau's study established that obese women had significantly reduced nighttime melatonin production [29], similar to our results for obese youths. This finding, along with a low level of melatonin in the evening, may indicate a change in the rhythm of this hormone production. Melatonin concentration normally begins to increase 1-2 hours before the usual time of going to sleep [30]. Surprisingly, non-OSA obese patients had higher melatonin levels at 6 a.m. than adolescents with OSA and control subjects with NBM.

Our results are more consistent with one of the first studies on the circadian melatonin rhythms in obese adolescents, which demonstrated a high average melatonin level but, at the same time, revealed a shift in the maximum melatonin secretion towards early morning [31]. Wetterberg et al. [32] found that nighttime melatonin concentrations negatively correlated with BMI. However, our results are at odds with those of Wetterberg, as we observed only significant positive correlations between morning and noon (but not nighttime) melatonin levels and BMI in the non-OSA group of obese patients. Perhaps, this finding indicates that, at the stage of functional (reversible) disorders, the activation of compensatory mechanisms occurs, an integral component of which is the 
melatonin system, followed by depletion of reserve capabilities at the stage of somatic pathology formation.

No significant correlations were found between OSA-related PSG indicators and melatonin levels in the group of adolescents with no clinical manifestations of OSA, except for a positive correlation between the minimum $\mathrm{SaO}_{2}$ level and evening melatonin content. Meanwhile, patients with clinical manifestations of OSA exhibited additional correlations between nocturnal melatonin and minimum $\mathrm{SaO}_{2}$ levels, as well as between evening melatonin and time with $\mathrm{SaO}_{2}<90 \%$. Disruption of the sleep-wake cycle in OSA patients is connected to morning and afternoon sleepiness, along with mental and behavioral problems [33]. Sleep deprivation in adolescents also correlates with certain health problems [34]. In our study, more pronounced changes in circadian rhythms in adolescents with clinically significant OSA may explain the presence of the problems, associated with sleep and wakefulness.

Thus, we assume that, in conditions of obesity as an isolated pathology, there is a tendency to a shift in melatonin secretion towards the early morning, which indicates the participation of this hormone in the regulation of metabolic rhythms. When obesity is combined with OSA, the shift in melatonin secretion to the evening hours indicates the intensity of compensatory mechanisms that, in conjunction with some neurophysiological changes during sleep, may reflect an adaptive response to sleep fragmentation and intermittent nocturnal hypoxemia during episodes of apnea/hypopnea.

\section{Conclusion}

The results of our study indicated a change in circadian melatonin secretion of obese adolescents, both with and without OSA. However, in patients with clinical manifestations of OSA, more significant changes in melatonin production during the day were demonstrated, specifically, an increase in its level in the evening and production decrease at night. Our results emphasize the need to measure the circadian rhythm of melatonin secretion in obese adolescents with or without OSA which requires different approaches to treatment. New studies are needed to compare changes in circadian rhythm of melatonin production when different approaches are used to treat obese patients with or without OSA.

\section{Limitations}

The limitations of this study were related to the fact that small groups of adolescents were examined, given the incompetence of many potential participants who refused the upcoming PSG and saliva sampling, i.e. did not sign a voluntary informed consent. Hence, our results may differ from the results of studies with a larger sample size of obese patients.

\section{Conflict of interest}

The authors declare that there is no conflict of interest.

\section{Ethical approval}

The study was conducted in strict accordance with the Declaration of Helsinki (World Medical Association 2013), and the study protocol was approved by the Committee on Biomedical Ethics of SC FHHRP.

\section{Acknowledgements}

This work was performed with the use of equipment of Collective research centre "Center for the development of progressive personalized technologies for health" SC FHHRP, Irkutsk.

\section{References}

1. Trakada G, Nikolaidis PT, Economou NT, Sakkas D, Giagkou G, Sakellariou $S$, et al. A pilot study about the dysfunction of adipose tissue in male, sleep apneic patients in relation to psychological symptoms. Front Psychiatry 2019; 10: 527. https://doi.org/10.3389/fpsyt.2019.00527.

2. Wakabayashi $Y$, Oka R, Nakaya M, Karashima S, Kometani M, Sakurai $M$, et al. Associations between Sleep-Disordered Breathing and Metabolic Risk Factors beyond Obesity. J Diabetes Res 2018; 2018: 1567683. https://doi.org/10.1155/2018/1567683.

3. Fava MC, Agius R, Fava S. Obesity and cardio-metabolic health. $B r J$ $\begin{array}{llll}\text { Hosp Med (Lond) 2019; 80(8): 466-471. } & \text {. }\end{array}$ https://doi.org/10.12968/hmed.2019.80.8.466.

4. Cespedes Feliciano EM, Quante M, Rifas-Shiman SL, Redline S, Oken E, Taveras EM. Objective sleep characteristics and cardiometabolic health in young adolescents. Pediatrics 2018; 142(1): e20174085. https://doi.org/10.1542/peds.2017-4085.

5. Brzecka A, Piesiak P, Zareba-Bogdał E, Zierkiewicz G, Plamieniak Z. Rhythm of melatonin excretion in obstructive sleep apnoea syndrome. Pneumonol Alergol Pol 2001; 69: 650-654. Polish. https://pubmed.ncbi.nlm.nih.gov/12134441/.

6. Lemmer B, Scholtze J, Schmitt J. Circadian rhythms in blood pressure, heart rate, hormones, and on polysomnographic parameters in severe obstructive sleep apnea syndrome patients: effect of continuous positive airway pressure. Blood Press Monit 2016; 21(3): 136-143. https://doi.org/10.1097/mbp.0000000000000173.

7. Hernández $C$, Abreu J, Abreu $P$, Castro A, Jiménez A. Nocturnal melatonin plasma levels in patients with OSAS: the effect of CPAP. Eur Respir J 2007; 30(3): 496-500. https://doi.org/10.1183/09031936.00051906.

8. Arble DM, Bass J, Behn CD, Butler MP, Challet E, Czeisler C, et al. Impact of sleep and circadian disruption on energy balance and diabetes: a summary of workshop discussions. Sleep 2015; 38(12): 1849-1860. https://doi.org/10.5665/sleep.5226.

9. Ostrovskaya EV, Romantsova TI, Gerasimov AN, Novoselova TE. Dynamics of quality of life indicators associated with weight loss in patients with metabolically healthy obesity. Russian Open Medical Journal 2019; 8: e0309. https://doi.org/10.15275/rusomj.2019.0309.

10. Cipolla-Neto J, Amaral FGD. Melatonin as a Hormone: New Physiological and Clinical Insights. Endocr Rev 2018; 39(6): 990-1028. https://doi.org/10.1210/er.2018-00084.

11. Kolesnikova LI, Darenskaya MA, Grebenkina LA, Labygina AV, Suturina $\mathrm{LV}$, Dolgikh MI, et al. Activity of lipid peroxidation in infertile women from different populations. Bull Exp Biol Med 2012; 154(2): 203-205. https://doi.org/10.1007/s10517-012-1912-4.

12. Eckerberg B, Lowden A, Nagai R, Akerstedt T. Melatonin treatment effects on adolescent students' sleep timing and sleepiness in a placebo-controlled crossover study. Chronobiol Int 2012; 29(9): 12391248. https://doi.org/10.3109/07420528.2012.719962.

13. Zisapel N. New perspectives on the role of melatonin in human sleep, circadian rhythms and their regulation. Br J Pharmacol 2018; 175(16): 3190-3199. https://doi.org/10.1111/bph.14116.

14. Senaratna CV, English DR, Currier D, Perret JL, Lowe A, Lodge C, et al. Sleep apnea in Australian men: disease burden, co-morbidities, and correlates from the Australian longitudinal study on male health. $B M C$ Public Health 2016; 16(Suppl 3): 51-61. https://doi.org/10.1186/s12889-016-3703-8.

15. WHO. Obesity and overweight. Fact sheet. Growth reference 5-19 years. https://www.who.int/growthref/who2007 bmi for age/en. 
16. Kaditis AG, Alvarez MLA, Boudewyns A, Alexopoulos El, Ersu R, Joostenet $\mathrm{K}$, et al. Obstructive sleep disordered breathing in 2- to 18year-old children: diagnosis and management. Eur Respir J 2016; 47(1): 69-94. https://doi.org/10.1183/13993003.00385-2015.

17. Berry RB, Brooks R, Gamaldo CE, Harding SM, Lloyd RM, Marcus CL, et al. The AASM Manual for the scoring of sleep and associated events: rules, terminology and technical specifications, Version 2.2. Darien, Illinois: American Academy of Sleep Medicine, 2015; 79 p. https://aasm.org/resources/pdf/scoring-manual-preface.pdf.

18. Kolesnikova LI, Madayeva IM, Semenova NV, Suturina LV, Berdina ON, Sholokhov LF, et al. Pathogenetic Role of Melatonin in Sleep Disorders in Women of the Climacteric Period. Bull Exp Biol Med 2013; 156(7): 117-119. Russian. https://www.elibrary.ru/item.asp?id=19624021.

19. Barnaś M, Maskey-Warzęchowska M, Bielicki P, Kumor M, Chazan R. Diurnal and nocturnal serum melatonin concentrations after treatment with continuous positive airway pressure in patients with obstructive sleep apnea. Pol Arch Intrn Med 2017; 127(9): 589-596. https://doi.org/10.20452/pamw.4062.

20. Wikner J, Svanborg E, Wetterberg L, Röjdmark S. Melatonin secretion and excretion in patients with obstructive sleep apnea syndrome. Sleep 1997; 20(11): 1002-1007. https://doi.org/10.1093/sleep/20.11.1002.

21. Zirlik S, Hildner KM, Targosz A, Neurath MF, Fuchs FS, Brzozowski T, et al. Melatonin and omentin: influence factors in the obstructive sleep apnoea syndrome? J Physiol Pharmacol 2013; 64(3): 353-360. https://pubmed.ncbi.nlm.nih.gov/23959732/.

22. Hickie IB, Naismith SL, Robillard R, Scott EM, Hermens DF. Manipulating the sleep-wake cycle and circadian rhythms to improve clinical management of major depression. BMC Med 2013; 11: 79. https://doi.org/10.1186/1741-7015-11-79.

23. Carissimi A, Martins AC, Dresch F, da Silva LC, Zeni CP, Paz Hidalgo M. School start time influences melatonin and cortisol levels in children and adolescents - a community-based study. Chronobiol Int 2016; 33(10): 1400-1409. https://doi.org/10.1080/07420528.2016.1222537.

24. Loredo JS, Weng J, Ramos AR, Sotres-Alvarez D, Simonelli G, Talavera $\mathrm{GA}$, et al. Sleep patterns and obesity: Hispanic community health study/study of Latinos sueño ancillar study. Chest 2019; 156(2): 348356. https://doi.org/10.1016/j.chest.2018.12.004

25. Zhang Y, Zitsman JL, Hou J, Fennoy I, Guo K, Feinberg J, et al. Fat cell size and adipokine expression in relation to gender, depot, and metabolic risk factors in morbidly obese adolescents. Obesity (Silver Spring) 2014; 22(3): 691-697. https://doi.org/10.1002/oby.20528.

26. O'Neill S, O'Driscoll L. Metabolic syndrome: a closer look at the growing epidemic and its associated pathologies. Obes Rev 2015; 16(1): 1-12. https://doi.org/10.1111/obr.12229.

27. Szewczyk-Golec K, Rajewski P, Gackowski M, Mila-Kierzenkowska C, Wesołowski R, Sutkowy $\mathrm{P}$, et al. Melatonin supplementation lowers oxidative stress and regulates adipokines in obese patients on a calorie-restricted diet. Oxid Med Cell Longev 2017; 2017: 8494107. https://doi.org/10.1155/2017/8494107.

28. de Farias TDSM, Cruz MM, de Sa RCDC, Severi I, Perugini J, Senzacqua $M$, et al. Melatonin supplementation decreases hypertrophic obesity and Inflammation induced by high-fat diet in mice. Front Endocrinol (Lausanne) 2019; 10: 750. https://doi.org/10.3389/fendo.2019.00750.

29. Corbalán-Tutau D, Madrid JA, Nicolás JA, Garaulet M. Daily profile in two circadian markers "melatonin and cortisol" and associations with metabolic syndrome components. Physiol Behav 2014; 123: 231-235. https://doi.org/10.1016/i.physbeh.2012.06.005.

30. Zawilska JB, Skene DJ, Arendt J. Physiology and pharmacology of melatonin in relation to biological rhythms. Pharmacol Rep 2009; 61(3): 383-410. https://doi.org/10.1016/s1734-1140(09)70081-7.

31. Shafii M, MacMillan DR, Key MP, Kaufman N, Nahinsky ID. Case study: melatonin in severe obesity. J Am Acad Child Adolesc Psychiatry 1997; 36(3): 412-416 https://doi.org/10.1097/00004583-199703000-00021.
32. Wetterberg L, Bratlid T, von Knorring L, Eberhard G, Yuwiler A. A multinational study of the relationships between nighttime urinary melatonin production, age, gender, body size, and latitude. Eur Arch Psychiatry Clin Neurosci 1999; 249(5): 256-262. https://doi.org/10.1007/s004060050095.

33. Maspero C, Giannini L, Galbiati G, Rosso G, Farronato G. Obstructive sleep apnea syndrome: a literature review. Minerva Stomatol 2015; 64(2): 97-109. https://pubmed.ncbi.nlm.nih.gov/25747430/.

34. Paiva T, Gaspar T, Matos MG. Sleep deprivation in adolescents: correlations with health complaints and health-related quality of life. Sleep Med 2015;16(4): 521-527. https://doi.org/10.1016/i.sleep.2014.10.010.

\section{Authors:}

Olga N. Berdina - MD, PhD, Leading Researcher, Laboratory of Somnology and Neurophysiology, Scientific Centre for Family Health and Human Reproduction Problems, Irkutsk, Russia. http://orcid.org/0000-0003-09306543.

Irina M. Madaeva - MD, DSc, Head of the Laboratory of Somnology and Neurophysiology, Scientific Centre for Family Health and Human Reproduction Problems, Irkutsk, Russia. https://orcid.org/0000-0003-34237260.

Svetlana E. Bolshakova - MD, PhD, Researcher, Laboratory of Somnology and Neurophysiology, Scientific Centre for Family Health and Human Reproduction Problems, Irkutsk, Russia. http://orcid.org/0000-0002-31044212.

Maria V. Tsykunova - Pediatrician, Clinic of Scientific Centre for Family Health and Human Reproduction Problems, Irkutsk, Russia. https://orcid.org/0000-0002-9525-4833.

Leonid F. Sholokhov - MD, Dsc, Professor, Head of the Laboratory of Endocrine System Physiology and Pathology, Scientific Centre for Family Health and Human Reproduction Problems, Irkutsk, Russia. https://orcid.org/0000-0003-3588-6545.

Maria A. Rashidova - PhD, Researcher, Laboratory of Endocrine System Physiology and Pathology, Scientific Centre for Family Health and Human Reproduction Problems, Irkutsk, Russia. https://orcid.org/0000-0003-4730$\underline{5154}$

Olga V. Bugun - MD, DSc, Chief Physician at the Clinic of Scientific Centre for Family Health and Human Reproduction Problems, Irkutsk, Russia. http://orcid.org/0000-0002-2162-3683.

Lyubov V. Rychkova - MD, DSc, Corresponding Member of the Russian Academy of Sciences, Professor, Director of Scientific Centre for Family Health and Human Reproduction Problems, Irkutsk, Russia. http://orcid.org/0000-0001-5292-0907. 